\title{
Research on Modeling Characteristics and Composition Forms of Dunhuang Mural Art in Tang Dynasty
}

\author{
Diansheng Guo, Yan Liang \\ School of Art and Design, Lanzhou Jiaotong University, Lanzhou, 730070, China
}

Keywords: Modeling characteristics, Composition forms, Dunhuang mural art, Tang dynasty

\begin{abstract}
Dunhuang murals in Tang Dynasty embodied the essence of Dunhuang art. In the Tang Dynasty, the Dunhuang frescoes retained the traditional modeling features and composition forms, absorbed the advantages of the foreign culture and created the high-spirited artistic image. This article gives the features of buddha, figure and nature. The composition forms of central radiant, three segment and subsection narration are also analyzed in the article to provide some references for the relevant researchers.
\end{abstract}

\section{Introduction}

Liangzhou class forces overthrowed the Li Gui regime and Hexi were officially incorporated into the territory of Tang Dynasty After the establishment of the Tang Dynasty. In the Tang Dynasty of the Sui Dynasty after the annexation of Dunhuang county to Guazhou. At that time, the situation in Dunhuang was not stable, and the separatist forces were disturbed. The Tang Dynasty sent troops to Qinghai beat West Tuguhun, since the Hexi Corridor no difficulties outside on the stable development of the road was unified, Rui Taiwan political economic prosperity but also for the Dunhuang murals characters development has brought unprecedented prosperity since the Tang Dynasty Murals nearly two years of development and evolution of white with the history and culture of Hexi the area naturally appeared in a variety of atmosphere, which is one of the typical style of figure painting. The art of painting is not China figure painting figure painting color and line shape compared to the art of language and expression of the Tang Dynasty of Dunhuang murals in the use of more and more refined, the Dunhuang painting in the figures on further highlight the type of phase characteristics is poor as God can change. Dunhuang murals are mainly based on the characters which contain a large number of clothing and textile graphics have different historical styles including multi ethnic dress patterns which are full of the Silk Road in Dunhuang old glory. Dunhuang, located in ancient China to the western regions, Central Asia and Europe, the main road of transportation-the Silk Road, because of the broad and profound cultural connotations and is famous in the world, Dunhuang mural is the most distinctive branch of this bright culture. In the Tang Dynasty, the Tang Dynasty is a special period, after the decline of the great social background, coupled with the delicate position of the Dunhuang, making this period of the Dunhuang frescoes covered an indistinct mystery, the form and composition of the resulting features.

\section{Modeling Characteristics of Dunhuang Mural Art in Tang Dynasty}

Solemn Buddha. Since the Tang Dynasty, due to the unity of the country, while the exchange and integration of Dunhuang art and the Central Plains art, the Dunhuang murals quickly entered the period of rapid development. At that time, artists were able to skillfully use different means to create different works of excellence. The style and genre of Chinese painters have an important influence on the Dunhuang murals, and make the Dunhuang murals show a new situation of letting a hundred flowers bloom. There are many paintings in Dunhuang murals, such as the early period of the Tang Dynasty variable graph of the detailed record of the emperor king and Minister of the image, also recorded figure. These figures are very consistent with the dress code of the thirteen emperors. From the early Tang Dynasty to the Tang murals of Dunhuang have appeared in the imperial ceremony map. It is the Central Plains region of the popular drawings, and different forms of characters in each grotto 
murals. At the same time, in order to better reflect the different character style, the artist pays great attention to the personality in the character modelling. Tolerance and minister to the emperor that the king reserved a contemptuous disregard figure in the manner described and the corresponding image lifelike image, depicted the image of the western ethnic characters are different with vivid artistic charm. Therefore, the mural painting of Dunhuang in the Tang Dynasty depicts the characters of different nationalities, and expands the theme of figure painting. In addition, Buddhism and its art in the Tang Dynasty were introduced into China from India and other places, and at the beginning of the Dunhuang murals, many Chinese elements were integrated into the Chinese Buddhist art. After the Tang Dynasty, the Tang Dynasty Guanyin rendering rich luxurious, Ying Road no longer seems to be the only point to merit the characterization of ornaments, a statue of the Bodhisattva stage makeup.

Flying Figure. Flying over the wall of the wind is a very representative of the image of the Tang Dynasty Murals. These murals in the Western flying like a little angel, makes the picture more lively and vivid. During this period, the image of flying mostly relaxed demeanor, round face, body posture that fly very pretty and charming, elegant and flying belt together, reflects the wishes of the pursuit of freedom, the smooth lines, colorful colors have more romantic features figure paintings of Tang Dynasty reflect the unity of the pursuit of spirit. Flying more than painting in the tomb murals, a symbol of the tomb of the master's soul can be ascended to heaven. After the introduction of Buddhism into China, the integration of Taoism with china. Buddhism in the early spread of the Wei, Jin and Northern and Southern Dynasties.The murals have been flying in the cave of the four flying also known as flying, flying, flying cents. Later, with the further development of Buddhism in China, Taoism, Buddhism and the flying fly though into each other in the art image, but in name, only the Buddhist grotto murals in the sky called Kagura flying. Flying in Dunhuang is a painting in Dunhuang Grottoes in the fly, and later became a special term for the art of Dunhuang murals. To the Tang Dynasty, Dunhuang flying into a highly mature period, the image of art reached the most perfect stage. This period of Dunhuang flying has been less India, the western region flying style, is completely Chinese flying. The Tang Dynasty is a large Mogao Grottoes Sutra painting most Dynasty, the walls are almost large Sutra paintings occupy. Flying is also the main painting in the big picture. In the subject, as well as large Sutra paintings of the Buddha that scene, loose, dance, praise for support on the other hand, the large Buddhist heaven in Elysian Fields joy.

Vast Nature. As an important part of the painting, the animals and plants in the Tang Dynasty Murals reflect the different angles of the mural style, which is worthy of our study and study. As a favorite pet and vehicle, Tang became a frequent visitor to the painting. At the same time, the study on the structure and movement of the horse is also made. "Zhang Yichao travel map" was in dozens of horses though the color attitude varies, but all tendons strong lines are described, showing these horses and vigorous torso and limbs. The tomb of Zhanghuai crown prince "map" the Polo horses are in high speed movement, vacated the hooves and strong muscles and forward head are just perfect showing is fast running horse image. However, unlike the early story painting with neat scroll screen separated, but according to the landscape constitute a natural layout, expanding the sense of space. However, this performance only for the activities of the people to provide a suitable scene, from the significance of landscape painting, but also far from the mountains and rivers to reach the realm of beauty. Even so, the performance of landscape space does have important influence on the Sutra painting pattern, which changed to full screen characters that early practice, and full of landscape space character is clear, focused. Not only shows the story, but also shows the beauty of mountains and rivers. The upper part of the screen, and the color green mountains corresponds to the orange colored clouds, like the afterglow of sunset, with a strike a deep chord force. From this shop, we can see the change of beam nirvana, the frescoes of the Tang Dynasty show story not only stay in the stories of graphic, and more attention to the mural as a visual art experience, and fully mobilize the techniques in landscape painting, reflects the magnificent artistic conception, to the beauty of the screen vertex. 


\section{Composition Forms of Dunhuang Mural Art in Tang Dynasty}

Central Radiant Form. The composition of the central radiation is the composition of the central form of the main body to the surrounding radiation. The picture in the central square composition subject in head in the clouds and mists, gorgeous trees canopy sitting on both sides, surrounded by many small Buddha, are down about the various screen above the clouds pavilions, terraces and open halls, the immortal Buddha head on each side of a flying upwind moving picture is blue the rippling lotus, the lower part of the eight fairy instruments in the play the wonderful music, a man dancing with the music, the graceful dance, ribbon dancing in the wind. The whole painting to the Buddha as the center to the surrounding radiation to extend a variety of scenery, composition appears plump, atmosphere, primary and secondary clear, the characters and the environment as a whole, while showing a deep, broad spatial effect. The immortal bird, lotus, gorgeous trees, makes the picture more rich and exquisite. Static Buddha, Bodhisattva, and dynamic flying, dancers formed a dynamic and static contrast, which is the Chinese side of the clever composition. When people stand in front of the painting, it will be this magnificent, rich composition and description of the shock and awe, immersive feel as if the audience can hear the beautiful moving music. In the Tang Dynasty, this pure land phase up to more than 200 pieces, each one has its own characteristics, but the composition form of the composition form has become one of the grand and magnificent frescoes of the Tang Dynasty is the representative.

Three Segment Form. According to the horizontal line is divided into three parts, the middle section is the description of the bottom of the scene depicts the net pool and platform, the platform is often the image of the upper and middle reaches of the symbol of the sky, flying image. The central part is the center of the picture, the platform of the Buddha and the Buddha around bodhisattva. The lower part is the net pool, the upper part is the sky. A central platform railings before the middle of the screen and the lower section are separated. Similar to the three section of this structure in the early Tang Dynasty Sutra painting is very popular, but the three paragraphs are gradually changing. As for the performance of the dancing scene, often with the lower part of the pool platform to replace. Can the cave of the Sutra, depicting the upper sky, the central portion of the draw on the platform that scene, depicting dancing scenes in the pool below the platform in figure. Such a composition in the cave, cave, cave in the pure land can be seen. The central argument is always the main figure change, to occupy a large screen, the lower part of the upper part of the sky dancing and the proportion is different. The upper and lower part of the sky dancing is very small, that scene center is large, building painting was also higher. But the Tang Dynasty dance scene, the proportion is more and more big. And that the dancing scene cannot do without the construction background, and through these architectural background shows the relationship between distance space. The uppermost part of the three segment, usually of the sky. In the Buddha's platform above the screen, with deep blue painting the sky, but also depicts a lot of flying around, making people feel the infinite space. Maitreya became content become very rich, such as farming, marriage chart of secular life scenes a lot, it's hard to picture clearly divided into three segments.

Subsection Narration Form. The "image narrative subject narrative Han Xizai banquet map" spread two topics: one is the image of Han Xizai, a double face preaching, satirical purposes. The two narrative theme spread cross now, basically break the chain of the order and the banquet activities clue narrative communication, but also broke the picture itself from the objective of right to left to "watch" line, also make the image narrative spread itself as much as possible to spread more content, the image narrative communication function to play to the maximum, thus, "Han Xizai evening banquet" become the image narrative works become an independent school, as experimental products may spread image narrative and the limit of almost beyond the image narrative communication model. , narrative history about "Han language group". A strong narrative communication network, and the "Han" image with each release, continue to strengthen communication analysis of a given meaning of accumulation. "Han" the true image and whether it has been drawing things, but almost no one to go into, and no one is willing to go to pay attention to the language of narrative about Its loopholes appeared one after another. wrong place, after all, the "reasonable" spread meaning enough. 
Together with the narrative language, "Han Xizai" image narrative in fact is also involved in the image reconstruction, the Han and the whole image thus, is also a kind of construction and dissemination of the history, "Han Xizai evening banquet" to show us a history of reading image and method of image reading history. The character of Han Xizai code has multiple roles, played a role in connection with a structural distinction between image narrative composition, other scenes and characters became a witness character and rendering style unique scenes, therefore, Han Xizai's image will avoid a surface consistent and could lead to a single scene.

\section{Conclusion}

As a unique art, Dunhuang mural art in Tang Dynasty has become the carrier of painting art. Many characters and the composition forms contain strong characteristics. The Dunhuang frescoes in the Tang Dynasty have a lasting artistic charm and a unique artistic effect. The study of the characteristics and composition of the Dunhuang frescoes in Tang Dynasty can help us to understand the form of Chinese painting deeply.

\section{Acknowledgements}

This research is the supported by the Natural Science Foundation of Gansu Province (Grant No. 1610RJZA045).

\section{References}

[1] Luo Hongqiang, The development and influence of dunhuang murals on modern figure painting [J]. China Building Materials Science \& Technology, 2017(1): 132-133.

[2] Ma Tao, Female Figures Depicted in Zhang Daqian’s Dunhuang Murals [J]. Hundred Schools in Arts [J]. 2015(S2): 135-137.

[3] Hu Faqiang, Tang-Dynasty Costumes and Culture in Dunhuang Murals-Take Dunhuang, Kizil, Bozi Kerik as an example [J]. Journal of Jinzhong University, 2008, 6(2): 41-45.

[4] Tian Hua, Study of the Floral Jewelry of Dunhuang Mogaoku Murals in the Tang Dynasty [J]. Art \& Design, 2009(4):114-115. 